\title{
OCUPACIONES AGROPASTORILES TEMPRANAS AL SUR DE LA QUEBRADA DE HUMAHUACA (JUJUY, ARGENTINA)
}

\author{
EARLY AGROPASTORAL OCCUPATIONS IN THE SOUTH OF THE \\ QUEBRADA OF HUMAHUACA (JUJUY, ARGENTINA)
}

\author{
Mercedes Garay de Fumagalli* y María Beatriz Cremonte**
}

\begin{abstract}
Se presentan nuevas evidencias sobre asentamientos formativos ubicados entre Volcán y el valle de Jujuy. Esta zona incluye a la porción meridional de la quebrada de Humahuaca (prepuna) y a las yungas occidentales (bosque montano y su transición al bosque chaqueño). Las ocupaciones agropastoriles comentadas en este artículo presentan registros arqueológicos que las diferencian de sitios contemporáneos conocidos en la quebrada de Humahuaca. La ocupación temprana hallada por debajo del Pukara de Volcán (períodos de los Desarrollos Regionales e Inka), los sitios de Trigo Pampa, Lozano y San Pablo de Reyes manifiestan algunas variaciones en sus emplazamientos y contextos cerámicos. Se proponen algunas hipótesis sobre las características de estos sitios en relación con la tradición San Francisco.
\end{abstract}

Palabras claves: Formativo, ambiente, cerámica, San Francisco.

New evidence regarding about Formative settlements located between Volcán and Jujuy Valley is presented. This zone includes the southern section of the Quebrada de Humahuaca (Prepuna) and the western yungas (Bosque Montano and its transition to the Monte Chaqueño). The agropastoralist occupations defined in this article have archaeological records that differentiate them from contemporaneous sites found in the Quebrada de Humahuaca. The early occupation located below the Pukara of Volcán (Desarrollos Regionales and Inka periods), Trigo Pampa, Lozano and San Pablo de Reyes sites, show some variations in their settlement locations and ceramic contexts. Some hypotheses regarding these site traits in relation to the San Francisco Tradition are discussed.

Key words: Formative, environment, ceramic, San Francisco.

En este trabajo se dan a conocer cuatro instalaciones del período Formativo, tres de ellas asignables a la tradición San Francisco y otra que presenta afinidades con la misma. Importa señalar que dichas instalaciones se encuentran emplazadas fuera del área nuclear ${ }^{1}$ de esta tradición, en un medio ambiente claramente diferente del que caracteriza a las tierras bajas. Las nuevas evidencias que se presentan en esta oportunidad aportan datos sobre procesos de complejidad creciente en estas sociedades, al mostrar asentamientos agropastoriles tempranos emplazados, como hemos dicho, lejos del área nuclear, que evidenciarían la explotación y control de nuevos territorios y de vías de interacción a mediana y larga distancia con sociedades coetáneas.

La amplia dispersión espacial del San Francisco es conocida en el Noroeste Argentino (NOA) a través de su estilo cerámico claramente definido, presente en numerosos asentamientos formativos, indicando en la mayoría de los casos situaciones de contacto. En este sentido, las investigaciones realizadas en Volcán aportan evidencias de ocupaciones efectivas en territorios considerados marginales para estas sociedades, con cronologías contemporáneas a las ocupaciones del valle del río homónimo. Por lo antedicho, consideramos que nuestro aporte abre una nueva perspectiva de análisis sobre el grado de complejidad social y de organización y uso del espacio de estas sociedades, que difiere del modelo de carácter difusionista planteado por Dougherty (1974b, 1975), que asigna a los asentamientos en áreas marginales un carácter tardío y decadente.

Los estudios referidos a comunidades formativas de la Provincia de Jujuy permitieron identificar una serie de asentamientos de tal carácter ubicados en la quebrada de Humahuaca y subsidiarias, en la puna y en el valle del río San Francisco, desconociéndose, hasta ahora, sitios tempranos en el sur de la quebrada y en el valle de Jujuy. Cada uno de estos desarrollos fue estudiado en su ámbito,

$\begin{array}{ll}* & \text { CREA-Facultad de Humanidades y Ciencias Sociales. UNJU. Otero 262-4600 San Salvador de Jujuy. fuma@imagine.com.ar } \\ \text { ** } & \text { CONICET. Instituto de Geología y Minería. UNJU. Av. Bolivia 1661-4600 San Salvador de Jujuy. cremonte@ @idgym.unju.edu.ar }\end{array}$ 
con relación al medio ambiente y los recursos propios de la zona, lográndose delimitar, así, territorios bastante definidos para cada uno de ellos (Dougherty 1974a, 1975, 1977; Hernández Llosas et al. 1985; Madrazo 1969; Olivera y Palma 1992). Se avanzó en menor medida en el estudio de los procesos de interacción entre sociedades formativas de la quebrada de Humahuaca y del valle del río San Francisco, a pesar de que en el registro arqueológico surgían evidencias referidas a la presencia de bienes de yungas en contextos quebradeños y aún en oasis altiplánicos como Toconao y San Pedro de Atacama, si bien varios autores llamaron reiteradamente la atención sobre este hecho (González 1963; Núñez y Dillehay 1995; Pérez Gollán 1973, entre otros).

En el presente trabajo presentamos nuevas evidencias acerca de asentamientos humanos pertenecientes al Formativo, ubicados en los valles sudorientales de Jujuy, a partir del $23^{\circ} 40^{\prime}$ lat. S., como así también de una instalación San Francisco por debajo de la ocupación tardía del Pukara de Volcán, en un medio ambiente prepuneño. Todos ellos están instalados en cotas más bajas que las conocidas hasta ahora para otros sitios tempranos de la quebrada y presentan diferencias en los contextos cerámicos y en el patrón de instalación, respecto a los anteriores.

Estos sitios son: Trigo Pampa, situado a 1.600 msnm, sobre una terraza cuaternaria del arroyo homónimo, $10 \mathrm{~km}$ al oeste de la actual localidad de Ocloyas a los $65^{\circ} 13^{\prime}$ long. O. y $23^{\circ} 46^{\prime}$ lat. S., Lozano (Loz.1), a $1.450 \mathrm{msnm}$ sobre una terraza del río Grande y cerca de la margen izquierda del río Lozano, en la desembocadura en el río Grande a los $65^{\circ} 24^{\prime}$ long. O. y $24^{\circ} 04^{\prime}$ lat. S. San Pablo de Reyes, emplazado también sobre una antigua terraza del río Grande, situada en la margen derecha del mismo, a 1.400 msnm rodeado por los arroyos San Pablo y Barcaza, a los $65^{\circ} 19^{\prime}$ long. O. y $24^{\circ}$ $07^{\prime}$ lat. S. y el asentamiento temprano de Volcán, ubicado por debajo del Pukara de Volcán a los $65^{\circ}$ $24^{\prime}$ long. O. y $23^{\circ} 45^{\prime}$ lat. S. (Figura 1 ).

Tarragó (1992) presentó un modelo para el Formativo en el Noroeste Argentino, donde planteó cuatro alternativas que comprenden los tipos de instalación de las aldeas agropastoriles tempranas. Los sitios referidos corresponden al segundo tipo "posición de ecotono entre quebradas áridas y valles húmedos del este" (Tarragó 1992: 307), dado que la quebrada de Humahuaca y sus bordes son en sí un ecotono con estas características. Sin embargo, lo más significativo de estos sitios es que todos se relacionan, según mecanismos que analizaremos a continuación, con los originados en el valle del río San Francisco y que corresponderían al tercer tipo de los planteados por Tarragó: "intersección en cuencas hidrográficas de envergadura" (Tarragó 1992: 307)². Esta relación con la tradición San Francisco confiere una idiosincrasia particular a los asentamientos y, por lo tanto, a la ocupación temprana en el sector sur de la quebrada de Humahuaca, que consideramos está relacionada con la configuración espacial de esta región.

\section{La Tradición San Francisco}

Las primeras menciones sobre la tradición San Francisco se deben a Nordenskiöld (1903) y Boman (1908). Serrano (1962) caracteriza el sector norte del "área subandina" como la cuna de la "Cultura Subandina del Chaco Occidental", "Cultura Santa Bárbara" o "Cultura San Francisco", los tres nombres con que la designa y a la que define por sus tipos cerámicos: Arroyo del Medio y El Infante. En cuanto a su cronología, la ubica en fechas antiguas, considerando que posee elementos distintivos respecto a las culturas agrícolas más evolucionadas. Por analogía supone que se corresponde con "los antiguos niveles de La Ciénaga y Candelaria, es decir que se remonta al año 250 de nuestra era, según el radiocarbono" (Serrano 1962: 42).

El estudio sistemático y profundo de estas manifestaciones se debe a Dougherty quien, desde 1970, dedicó todo su esfuerzo a la indagación de la arqueología del valle del río San Francisco y regiones aledañas. Desde esa fecha, ya cuestiona el término "cultura" utilizado por Serrano por considerar que "la variación interna de la subregión San Francisco, es mayor que la que podría ser incluida dentro del criterio de cultura, tal como ha sido descripta por Tylor (1948)" (Dougherty 1975: 373). Aplicando un criterio más tecnológico, propone denominar a estas manifestaciones como "Complejo Alfarero San Francisco" (Dougherty 1974b). Posteriormente lo llamará "Complejo Arqueológico San Francisco" (Dougherty 1975) y más tarde “Tradición San Francisco" (Dougherty 1977).

Con el avance de sus investigaciones, Dougherty descubre instalaciones San Francisco en otros ecosistemas, diferentes a los que caracterizan a la zona central, con lo cual afirma que la dispersión 


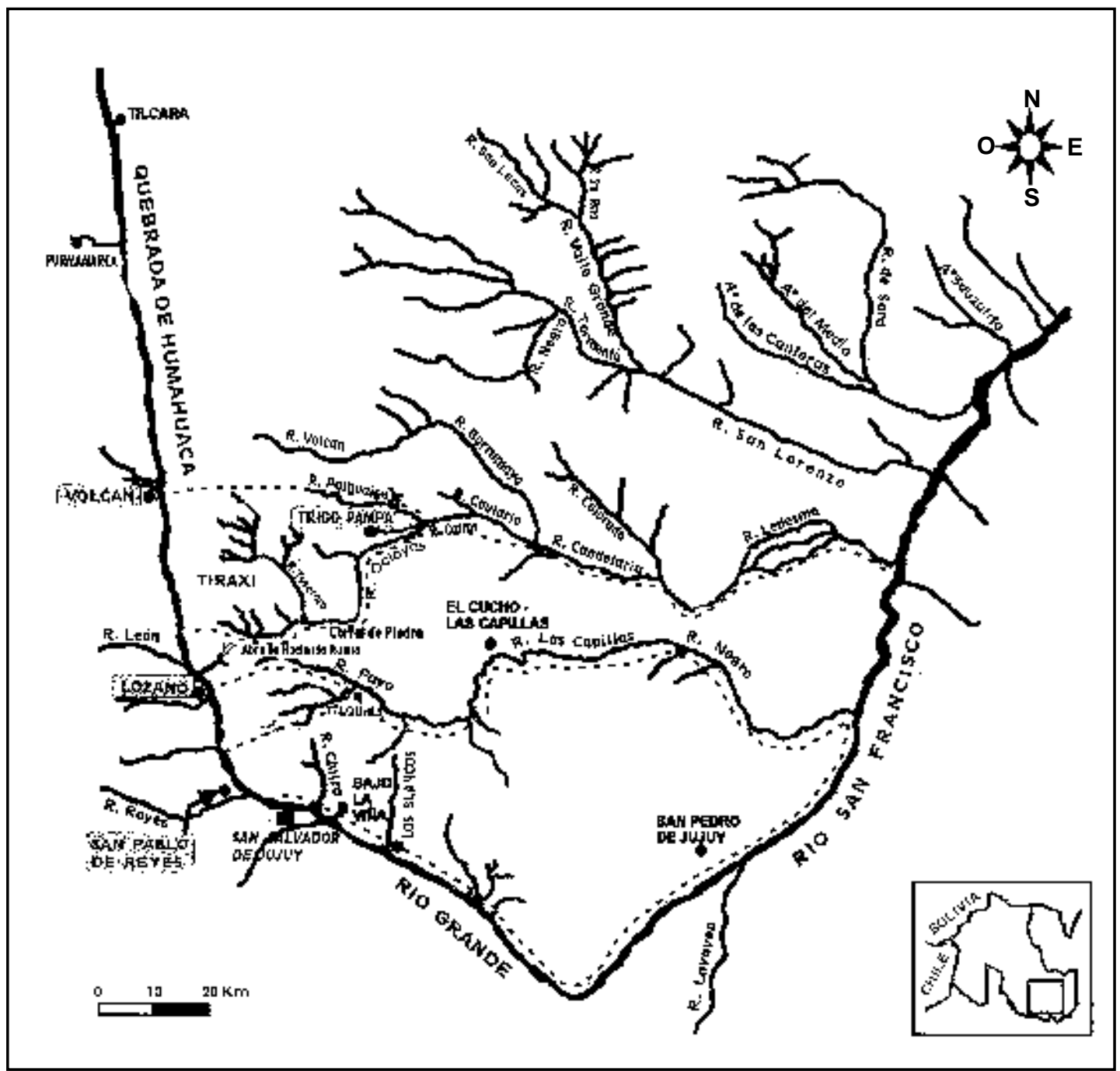

Figura 1. Mapa del sector sur de la quebrada de Humahuaca y valles orientales.

Map of the southern section of quebrada de Humahuaca and eastern valleys.

espacio-temporal del complejo es mucho mayor que la que se suponía y que llevó a concebir a estas manifestaciones como una cultura por parte de Serrano. Dougherty interpreta esta variación como producto de la dispersión y adaptación a nuevos ambientes por parte de representantes de una antigua tradición cultural que se expanden en dirección norte-sur, a lo largo del cauce del río San Francisco y que, ascendiendo por las cuencas de los ríos y arroyos subsidiarios, hacia el este y el oeste, ocupan los ecosistemas a los que hicimos referencia. También observa que este proceso de variación cultural interna ha quedado reflejado en los conjuntos cerámicos que "muestran un gradual empobrecimiento de los cánones tecnológicos y artísticos definidos en el sector central" (Dougherty 1974b: 2) y que dicho empobrecimiento guarda relación directa con el grado de alejamiento del asentamiento estudiado. Como ejemplo de lo anterior menciona cuatro yacimientos: Capillas-El Cucho; PA II en Palpalá; El Rey I y Lomas de Olmedo. También especifica que "los tres primeros muestran una disminución abrupta en el porcentaje de los fragmentos alfareros asignables al grupo San Francisco Pulido (S.F. Pulido), con respecto al valle del río San Francisco, en tanto Palpalá y Lomas de Olmedo muestran asociación con materiales que pueden ser considerados alóctonos al Complejo y 
su área de dispersión" (Dougherty 1974b: 2). Basado en las observaciones comentadas, el mismo autor procede a realizar una sectorización medioambiental de la subárea San Francisco, a la que caracteriza por sus condiciones ecológicas y por los sitios arqueológicos detectados. Delimita ocho regiones, de las cuales nos interesa destacar dos con relación al presente trabajo: el sector San Pedro-El Carmen-Palpalá y el sector Las CapillasEl Cucho (Dougherty 1974b).

Al primer sector, ubicado en el cauce medio y final del río Lavallén y faja central de la Provincia de Salta, le asigna un desarrollo desde el 100 a.C. al 1 d.C. en razón de su hipótesis sobre desplazamiento y considera que está vinculado estilísticamente al Complejo San Francisco, por su grupo S.F. Pulido. Destaca que en los materiales recuperados en San Pedro, Palpalá y El Carmen se ven grandes afinidades con elementos alfareros de la cultura Condorhuasi y Candelaria. Los sitios propuestos como propios de este sector son los ubicados en los alrededores de San Pedro, Palpalá, Pucarita, Monterrico y Puesto Viejo en el Departamento El Carmen de la Provincia de Jujuy.

El segundo sector que presenta interés con relación a nuestras investigaciones es el de Las Capillas-El Cucho, ubicado en las cabeceras del río Negro, sobre los ríos homónimos. En esta región boscosa, que se desarrolla al oriente del departamento Capital, recupera materiales característicos del S.F. Ordinario, junto con materiales propios de los Desarrollos Regionales de la quebrada de Humahuaca e incaicos, entre los que destaca alfarerías pertenecientes al estilo Angosto Chico Inciso. Este hecho lo explica considerando que Las Capillas fue transitado en una época que podría remontarse al 300 d.C. y luego fue utilizado hacia finales de la época prehispánica por otros grupos provenientes del oeste.

Para este sector, Dougherty postula además que los sitios alejados del eje central, constituido por el río San Francisco, pueden haber tenido contactos, debido a una mayor permanencia en el sector con grupos cronológicamente más tardíos. Por lo tanto los habitantes de las cabeceras de los ríos Ledesma (Corral de Piedra) y Negro (Las Capillas) pudieron recibir influencias de grupos provenientes de la quebrada de Humahuaca, que se habrían visto reflejadas en su contexto sociocultural. Para estos sitios, "por correlación con el desarrollo cultural en esta subregión se propone una épo- ca fluctuante entre el 400 y el 500 d.C." (Dougherty et al. 1984: 215).

El análisis de Dougherty es el único que avanza sobre posibles procesos de interacción entre las sociedades San Francisco con otras coetáneas, aunque no haya estado planteado en estos términos. Asimismo, postula que otros contactos con la quebrada de Humahuaca pudieron producirse más al sur, debido a las similitudes ambientales entre el valle de San Pedro de Jujuy y el de Reyes. Sin embargo, la interrupción de sus trabajos le impidió plantear otros mecanismos de interacción y dispersión de estas sociedades.

Existe consenso en considerar que los asentamientos San Francisco cubrieron un rango temporal comprendido entre aproximadamente el 700 a.C. y el 300 d.C. La perduración de por lo menos 1.000 años de estas manifestaciones culturales (casi sin variaciones en sus conjuntos ergológicos) en un amplísimo sector de las Selvas Occidentales permite connotarlas como integrantes de una tradición. Sin embargo, a pesar de las décadas transcurridas desde su identificación, son muy escasas las dataciones absolutas conocidas para la subárea San Francisco, en gran parte debido a la escasez de investigaciones sistemáticas en la zona, a la poca potencia estratigráfica correspondiente a las ocupaciones de la región explorada hasta el presente y a la mala preservación del registro arqueológico no alfarero. Situaciones que, con excepción de Volcán, se reiteran en los otros tres sitios que presentamos en este trabajo, en los cuales no fue posible obtener muestras para dataciones radiocarbónicas. Tal como señala Ortiz (1997), las deficiencias en el conocimiento del registro arqueológico del San Francisco se reflejan en la ausencia de secuencias locales, la escasez de dataciones absolutas, carencia de estudios paleoclimáticos y ausencia de registros sistemáticos sobre la estructura formal, cuantitativa y distribucional del paisaje arqueológico. Los fechados radiocarbónicos dados a conocer hasta ahora para sitios de la subárea San Francisco se resumen en la Tabla 1.

Del listado de fechados surge que el panorama cronológico de la subárea San Francisco es aún complejo e incompleto; para la mayoría de los sitios se cuenta con un solo fechado y varios de ellos sin calibración. Según los autores, el lapso de unos 900 años para El Fuerte (Departamento Santa Bárbara) se interpretaría a causa de una ocupación 
Tabla 1. Dataciones radiocarbónicas de la subárea San Francisco (NOA). Radiocarbon dating of the San Francisco subregion (NOA).

\begin{tabular}{|c|c|c|c|}
\hline Muestra & Sitio & Edad convencional & Edad calibrada \\
\hline $\begin{array}{l}\text { ANU-446. Carbón vegetal } \\
\text { (Dougherty 1975) }\end{array}$ & $\begin{array}{l}\text { Agua Negra (El Piquete- } \\
\text { Dto. Sta Bárbara-Jujuy) }\end{array}$ & $\begin{array}{l}2.570 \pm 80 \text { a.p. } \\
620 \pm 80 \text { a.C. }\end{array}$ & - \\
\hline $\begin{array}{l}\text { SI-6957. Carbón vegetal } \\
\text { (Fernández Distel 1988) }\end{array}$ & $\begin{array}{l}\text { Los Hornos } \\
\text { (Dto. San Pedro-Jujuy) }\end{array}$ & $\begin{array}{l}2.365 \pm 95 \text { a.p. } \\
415 \pm 95 \text { a.C. }\end{array}$ & - \\
\hline $\begin{array}{l}\text { Gak-9772. Carbón vegetal } \\
\text { (Fernández Distel 1994) }\end{array}$ & $\begin{array}{l}\text { Abra de Los Morteros } \\
\text { (Dto. Sta Bárbara-Jujuy) }\end{array}$ & $\begin{array}{l}3.460 \pm 110 \text { a.p. } \\
1.510 \pm 110 \text { a.C. }\end{array}$ & - \\
\hline $\begin{array}{l}\text { Beta-119821 } \\
(\text { Ortiz 2000) }\end{array}$ & $\begin{array}{l}\text { Finca Torino } \\
\text { (Dto. San Pedro-Jujuy) }\end{array}$ & $1.970 \pm 40$ a.p. & 40 a.C. \pm 70 d.C. \\
\hline $\begin{array}{l}\text { LP-596. Valvas perforadas } \\
\text { de gasterópodos } \\
\text { (Dougherty et al. 1999) }\end{array}$ & $\begin{array}{l}\text { El Fuerte } \\
\text { (Dto. Sta Bárbara-Jujuy) }\end{array}$ & $2.280 \pm 60$ a.p. & $550 \pm 70$ a.C. \\
\hline $\begin{array}{l}\text { LP-612. Oseo } \\
\text { (Dougherty et al. 1999) }\end{array}$ & $\begin{array}{l}\text { El Fuerte } \\
\text { (Dto. Sta Bárbara-Jujuy) }\end{array}$ & $1.740 \pm 55$ a.p. & $130 \pm 60$ a.C. \\
\hline $\begin{array}{l}\text { LP-618. Oseo } \\
\text { (Dougherty et al. 1999) }\end{array}$ & $\begin{array}{l}\text { El Fuerte } \\
\text { (Dto. Sta Bárbara-Jujuy) }\end{array}$ & $1.540 \pm 60$ a.p. & $330 \pm 70$ d.C. \\
\hline
\end{tabular}

extensa pero no continua. Esto explicaría la alta frecuencia de material cerámico recuperado y su correlación con una economía basada en la horticultura y con énfasis en la caza y recolección (Dougherty et al. 1999). Pero ciertamente, es necesario contar con información adicional sobre los procesos de formación del sitio para una mejor evaluación de su historia ocupacional.

Con relación al análisis de la cerámica San Francisco, Dougherty estableció dos grandes grupos: San Francisco Pulido (S.F. Pulido), equivalente en parte al grupo Arroyo del Medio de Serrano (1962), y el San Francisco Ordinario (S.F. Ordinario), también equivalente en parte al grupo El Infante del autor citado, proponiendo una vinculación estrecha y compleja entre ambos.

Al referirse a las pastas del grupo S.F. Pulido, Dougherty identificó los siguientes componentes: arena fina, tiestos molidos de hasta $2 \mathrm{~mm}$, roca granítica descompuesta, partículas de carbón y pajuelas de mica. Considera que las inclusiones de granito podrían indicar diferencias cronológicas y que las micas presentan un carácter más local en el sitio El Infante. Las pastas más comunes son negras, grises o marrones oscuras y minoritariamente rojo, ante o naranja. También el autor señala que la cocción es menos controlada en los sitios más alejados del eje del río San Francisco. Las vasijas de este grupo pueden estar incisas, pintadas o modeladas.

Las pastas del grupo S.F. Ordinario (Dougherty 1977: 243-245) presentan inclusiones finas a muy gruesas de arena, tiestos molidos de hasta $3,5 \mathrm{~mm}$, gravillas toscas molidas, raramente mica, roca granítica descompuesta (más común en el sitio Palpalá-II) y posiblemente carbón molido. Las pastas más comunes son negras o marrones, y minoritariamente de colores ante, rojo o naranja. Las superficies externas son rojas o naranjas y raramente marrones o negras. Pueden presentar una cobertura desleída, amarillenta o blancuzca. En general las superficies son medianamente ásperas $\mathrm{y}$ a veces recubiertas con revoque grueso con antiplástico de tiesto molido. La cocción es poco controlada y la decoración puede ser corrugada, incisa o por desplazamiento de arcilla. Los agregados plásticos no son comunes en los sitios San Francisco, se trata de representaciones zoomorfas emplazadas en las asas y son muy raras las caras antropomorfas con ojos en grano de café. 


\section{Características Diferenciales del Espacio en el Sur de la Quebrada de Humahuaca y sus Bordes}

La estructura geológica y la dirección de bloques dominantes en el sector meridional de la quebrada de Humahuaca y sus bordes, tanto oriental como occidental, determinan condiciones distintivas en el mismo, con relación al sector central y norte: (1) las unidades geomorfológicas de puna, quebrada y valles están más cercanas entre sí y las elevaciones serranas pierden altura progresivamente; (2) las condiciones medioambientales del sector meridional de la quebrada son más húmedas y templadas y las yungas se extienden hacia el oeste, atravesando el valle del río Grande a la altura de León; (3) los cauces del río Grande y del río San Francisco se acercan paulatinamente hacia el sur, dado que el primero, tras unirse con el río Lavayén, da origen al San Francisco.

Todas estas características geográficas han generado que en el sector meridional de la Quebrada los procesos de contacto con las tierras bajas y el valle del río San Francisco se vieran favorecidos por las condiciones descriptas. Estos contactos se han realizado fundamentalmente por las siguientes vías de comunicación de sur a norte: la cuenca del río Grande de San Pedro-valle de Jujuy; el río Negro y sus cabeceras: (río Capillas-Cucho); el río Ledesma y sus cabeceras (la cuenca del río Corral de Piedra) $)^{3}$.

En cuanto a la comunicación con el Pukara de Volcán, la tercera vía es la más expedita. A partir de la cuenca del río Ocloyas, la misma ofrece dos alternativas. La más directa y usada ha sido la que comunica este río con las localidades de San Javier, San Bernardo y quebrada de Huajra. Pero también es posible acceder desde el río Ocloyas al Corral de Piedra; Tiraxi Grande y de allí por la quebrada de Jaire, a la quebrada de Humahuaca, $20 \mathrm{~km}$ al sur de Volcán (Figura 1).

\section{Sitios del Sur de la Quebrada de Humahuaca y Valles Sudorientales}

\section{Volcán}

En un cono volcado transversal a la quebrada de Humahuaca, a $2.080 \mathrm{msnm}$, por debajo de los niveles de ocupación tardíos correspondientes al Pukara de Volcán, se detectó otra ocupación humana, propia del Formativo, que fue datada oportunamente en:
Tum1B3 31-6.a: $1940 \pm 40$ a.p., Beta-119669 Standard-AMS, carbón vegetal.

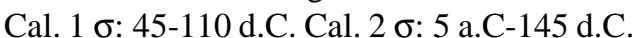

Tum1B3 30-7.a: 1940 \pm 70 a.p., Beta- 119670 Standard extended counted time, carbón vegetal.

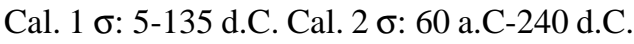

Para las calibraciones se utilizó el método de Stuiver y Reimer (1993).

Dicha ocupación se encuentra a 2 metros de profundidad, bajo el piso de formación de un basurero correspondiente a los Desarrollos Regionales e Inka (TUM 1-B3). El evento tiene una potencia de $0,80 \mathrm{~m}$. De los siete estratos excavados, los dos primeros arrojaron escaso material, el que aumenta notoriamente en los niveles VI y VII, sobre el piso de ocupación. El registro arqueológico de estos niveles está conformado exclusivamente por material cerámico (Figura 2).

De los niveles excavados, se recuperaron 594 fragmentos cerámicos (61 decorados y 27 bordes), correspondientes a los grupos S.F. Ordinario (44\%), S.F. Pulido (37\%) y a los Tardíos: Negro sobre Rojo, Pucos con Interior Negro y Ordinarios (19\%), presentes en los niveles superiores de las dos cuadrículas excavadas. Es importante señalar que los 40 fragmentos con decoración incisa S.F. Pulido Gris Inciso corresponden por lo menos a unas 20 vasijas diferentes. Los fragmentos cerámicos no son buenos indicadores de las formas completas de las vasijas, pero podemos decir que están presentes: escudillas evertidas de perfil simple y compuesto y subconvexas de perfil compuesto; pucos evertidos asimétricos de perfil inflexo; botellas subglobulares de cuello restringido con perfil inflexo o compuesto; ollas de contorno inflexo y probables vasos pequeños y medianos cilíndricos o subcilíndricos. Las bases son planas y algunos bordes presentan engrosamiento externo "en coma". Las formas coinciden en gran medida con las registradas por Ortiz (1997) para San Pedro de Jujuy. No se recuperaron fragmentos de pipas.

Los fragmentos decorados presentan los siguientes motivos: (1) líneas paralelas incisas finas, medianas o gruesas. En un fragmento formando haces de cinco líneas rellenas con pintura roja (S.F. Pulido Gris Inciso); (2) línea incisa perimetral al borde formando un surco de $5 \mathrm{~mm}$ de ancho en el gollete de un probable botellón (S.F. Pulido Gris Inciso); (3) línea perimetral incisa asociada con hilera de incisiones ovales (S.F. Ordinario); (4) líneas incisas anchas formando ángulos agudos pa- 


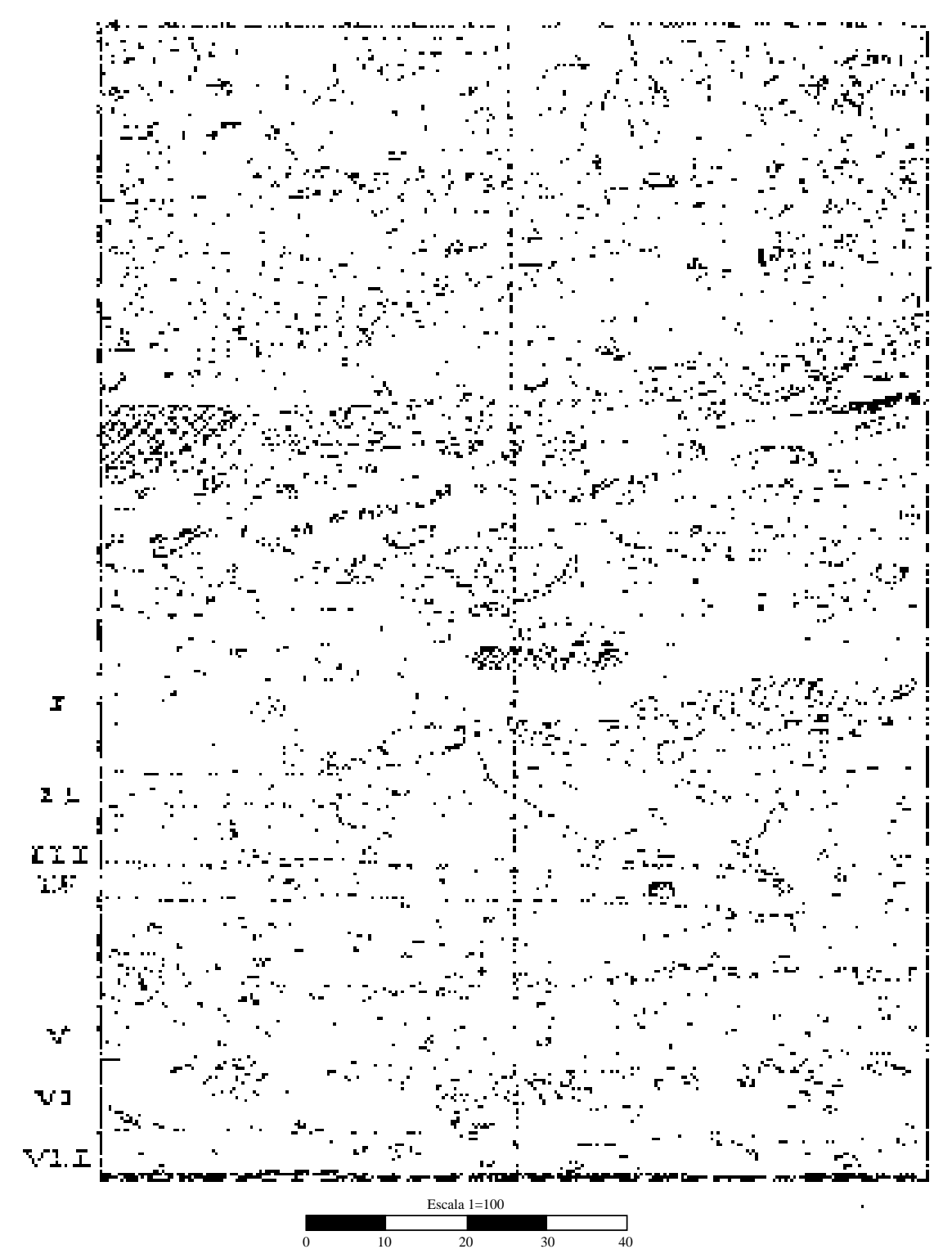

Figura 2. Perfil sitio TUM 1 (Pukara de Volcán) B-3. Cuadrícula A- perfil norte. Profile of TUM 1 site (Pukara de Volcán) B-3. Grid square A- north face profile.

ralelos (con o sin relleno de puntos incisos) o como haces de líneas en diferentes direcciones (S.F. Pulido Gris Inciso); (5) rombos rellenos con puntos delimitados por líneas verticales paralelas. Los trazos son finos y desprolijos (Gris Pulido Negro Inciso); (6) ángulos rellenos con líneas incisas paralelas horizontales delimitados por líneas verticales, algunas con relleno de puntos. Este motivo corresponde a la decoración externa de una escudilla compuesta con mamelón en la base del asa en cinta (S. F. Pulido Gris Inciso); (7) triángulo inciso en línea fina (desprolijo), rellenado con líneas cortas incisas (S.F. Pulido Gris Inciso); (8) impresión de cordel vegetal retorcido por debajo del borde, asociado con tira aplicada con impresiones unguiculares gruesas y oblicuas (S.F. Pulido Gris Inciso); (9) impresiones unguiculares en hilera por debajo de bordes con engrosamiento externo (S.F. Pulido Gris Inciso); (10) impresiones unguiculares muy pequeñas y delgadas en hileras (S.F. Pulido Gris Inciso); (11) hilera de incisiones arrastradas paralelas formando un collar alrededor del borde de una escu- 
dilla de perfil compuesto (S.F. Ordinario); (12) corrugado poco visible de tipo imbricado. Se trata de tiras superpuestas y luego pulidas (S.F. Pulido Gris Inciso); (13) líneas incisas finas paralelas, a ambos lados del motivo la superficie presenta engobe naranja rojizo pulido (S.F. Pulido Rojo sobre Ante); (14) líneas gruesas quebradas de color rojo morado sobre engobe amarillento pulido (S.F. Pulido Bicolor); (15) líneas paralelas verticales pintadas en rojo morado sobre el color natural de la pared (S.F. Pulido Bicolor); (16) representación zoomorfa modelada (¿lechuza?) con ojos en grano de café y con rastros de pintura roja (S.F. Pulido) (Figura 3).
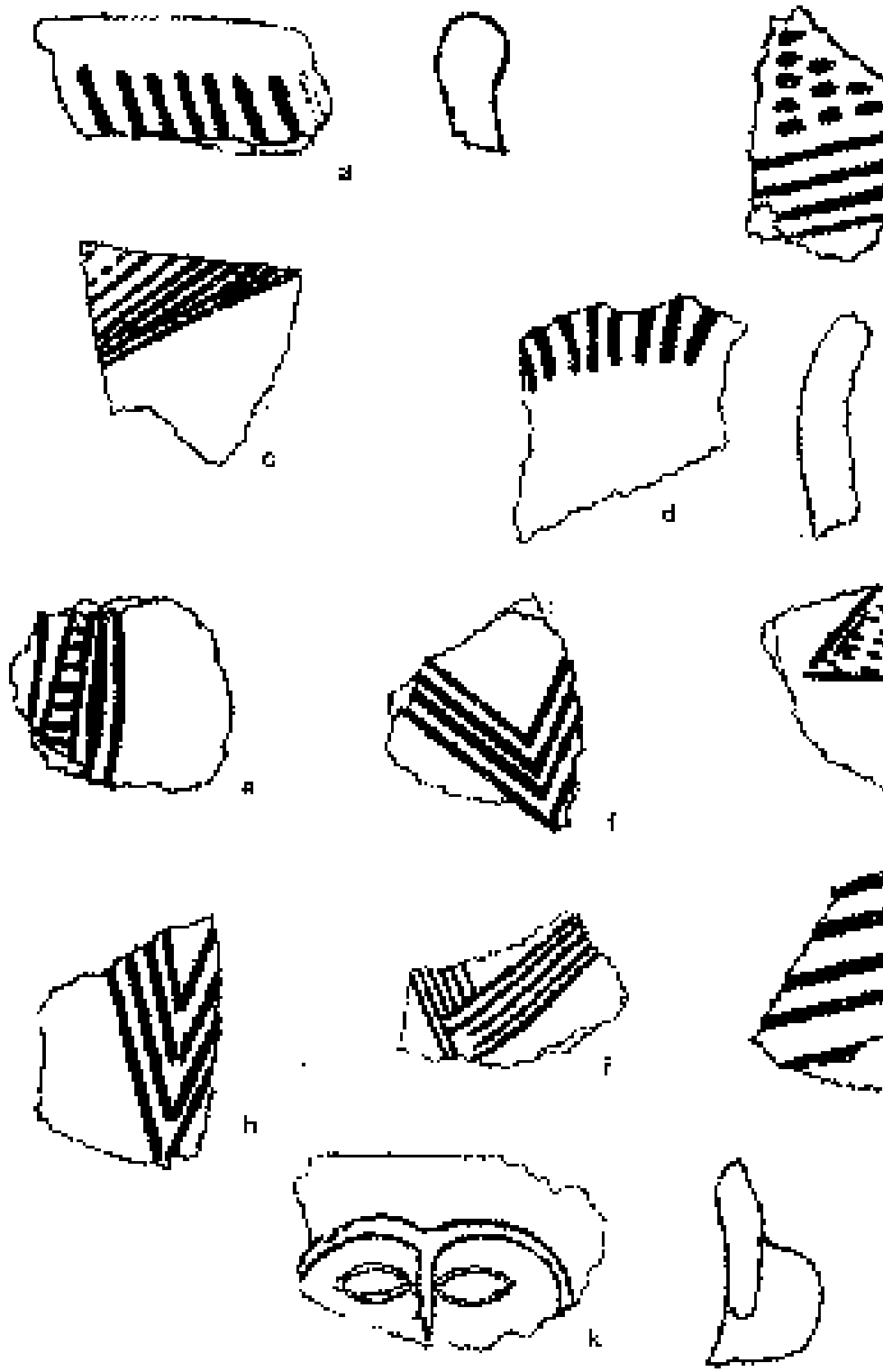
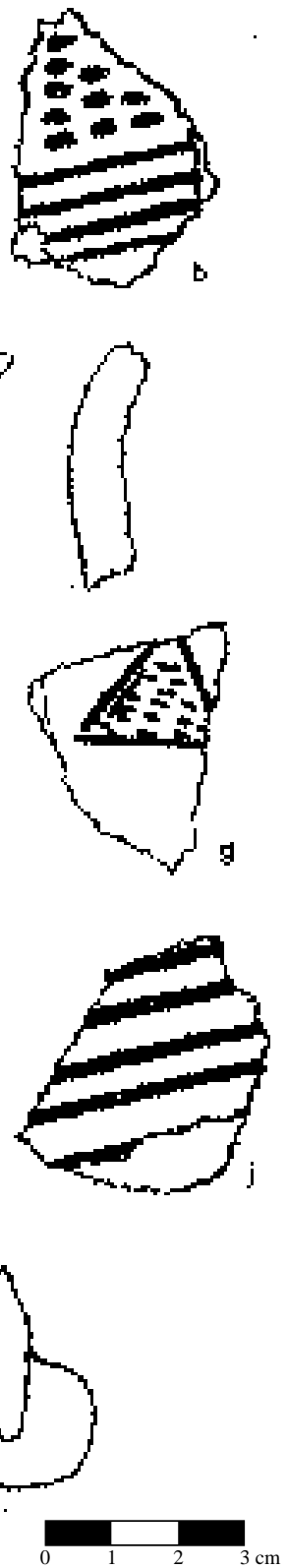

Figura 3. Cerámica de Volcán: a y d: San Francisco Pulido Bicolor; b, c, e, f, g, h, i, j: San Francisco Gris Pulido Inciso; y k: San Francisco Pulido Castaño.

Volcán pottery: a and d: San Francisco Pulido Bicolor; $b, c, e, f, g, h, i, j$ : San Francisco Gris Pulido Inciso; and k: San Francisco Pulido Castaño. 
En Volcán están presentes las pastas finas con tiestos molidos, las pastas gruesas con granito molido y las pastas medias con arena y porcentajes variables de tiesto molido. La mayoría de las pastas S.F. Pulido Gris Inciso corresponden a estas últimas, sin embargo, no existe una clara correlación entre tipos cerámicos y tipos de pastas. Las pastas de Volcán son muy similares a la de los tipos San Francisco de San Pedro de Jujuy. Con base en el análisis petrográfico pudieron determinarse cuatro grupos. En el Grupo 1, los componentes predominantes corresponden a fragmentos de rocas graníticas (tipo dioritas o granodioritas) y están presente en los tipos: S.F. Pulido Rojo/Ante, S.F. Pulido Negro Liso, y S.F. Ordinario. En el Grupo 2 el componente predominante es tiesto molido y está presente en los tipos S.F. Pulido (castaño claro), S.F. Pulido Gris Inciso, S.F. Pulido Bicolor. En el Grupo 3, las inclusiones predominantes corresponden a arena y la cantidad de tiesto molido es baja: S.F. Pulido Gris Inciso. Por último, en el Grupo 4 las inclusiones predominantes corresponden a tiesto molido y arena: S.F. Pulido Gris Inciso (castaño grisáceo) y S.F. Pulido Negro Inciso. Otros tipos cerámicos presentes son el Rojo Ordinario, Rojo Alisado y Castaño Alisado (Cremonte y Fumagalli 1999).

En su momento, interpretamos este sitio como producto de la instalación efectiva de grupos San Francisco. Los mismos habrían ocupado una topografía elevada y en un ambiente distinto del que caracteriza a los emplazamientos propios de estas sociedades. Esto, con el fin de captar nuevos territorios para obtener recursos alternativos, por ejemplo la ganadería de camélidos y también establecer bases territoriales para estimular los procesos de interacción con sociedades instaladas en otros ecosistemas, como las del borde oriental de la puna.

\section{San Pablo de Reyes}

El sitio es un montículo de escasa elevación, sin estructuras de muro en superficie ni en profundidad. Los hallazgos se recuperaron a partir de los $0,60 \mathrm{~m}$ desde la superficie actual del terreno hasta los 1,50 m. El material rescatado que es sólo alfarero, conforma una muestra representativa integrada en su $95 \%$ por fragmentos marrones, pardo amarillentos y grises alisados en los que pueden diferenciarse los siguientes tipos: Gris Claro Ordinario, de paredes medias y pastas gruesas con abun- dantes litoclastos de filitas (un borde levemente evertido presenta corrugamiento suave); Amarillento, de paredes delgadas con pastas de textura media con agregado de arena, pueden presentar cobertura roja muy desleída y la única forma corresponde a escudillas de perfil compuesto con decoración zonada en el borde a modo de finas líneas incisas verticales; Castaño Amarillento o Rojizo Micáceo, de paredes muy gruesas a medias con pastas de textura gruesa que indican el agregado de una elevada proporción de arena micácea gruesa, estas inclusiones son notorias en las superficies donde resaltan las laminillas brillantes de las micas. Las formas de este tipo corresponden a ollas globulares medianas de cuellos cortos levemente evertidos con asas dobles remachadas de sección rectangular, un fragmento de asa está decorado con líneas gruesas incisas paralelas; Marrón Ordinario, de paredes gruesas, con pastas y aspecto de las superficies similares a las del tipo anterior que también corresponden a ollas medianas a grandes; Marrón Alisado, de paredes delgadas y pastas bastante finas con escasas inclusiones de arena que parecen corresponder a vasos de tipo cilíndrico y probables botellones.

Los bordes son directos o ligeramente evertidos, algunos con refuerzo interno plano. Un cuello de botella presenta en la inserción con el cuerpo un modelado en ojo grano de café, otro fragmento gris negro micáceo de pasta gruesa con abundante cuarzo, corresponde a una cara modelada con tiras aplicadas con incisiones formando las cejas y ojos grano de café, similar a los modelados de la Fase 1 de Tafí (Núñez Regueiro y Azcárate 1996) y que fueran asignadas a Candelaria I (González 1963; Heredia 1975). Por último, un cuello de otra probable botella corresponde al tipo S.F. Pulido Gris Inciso y otro al Negro Inciso con registro de triángulos punteados en su interior (Garay de Fumagalli 1996) (Figura 4).

\section{Lozano (Loz-1)}

El sitio corresponde a un montículo, alterado por la acción de máquinas que trabajaron en el lugar construyendo un camino y que dejaron expuesto parte del material cultural. En el sector no alterado se realizó un sondeo de 2 x $1 \mathrm{~m}$. El nivel de ocupación apareció entre los 0,80 a $1 \mathrm{~m}$ de profundidad teniendo una potencia de $0,90 \mathrm{~m}$, sin estructuras de muro. Se recuperaron fragmentos de alfarería y material lítico. 


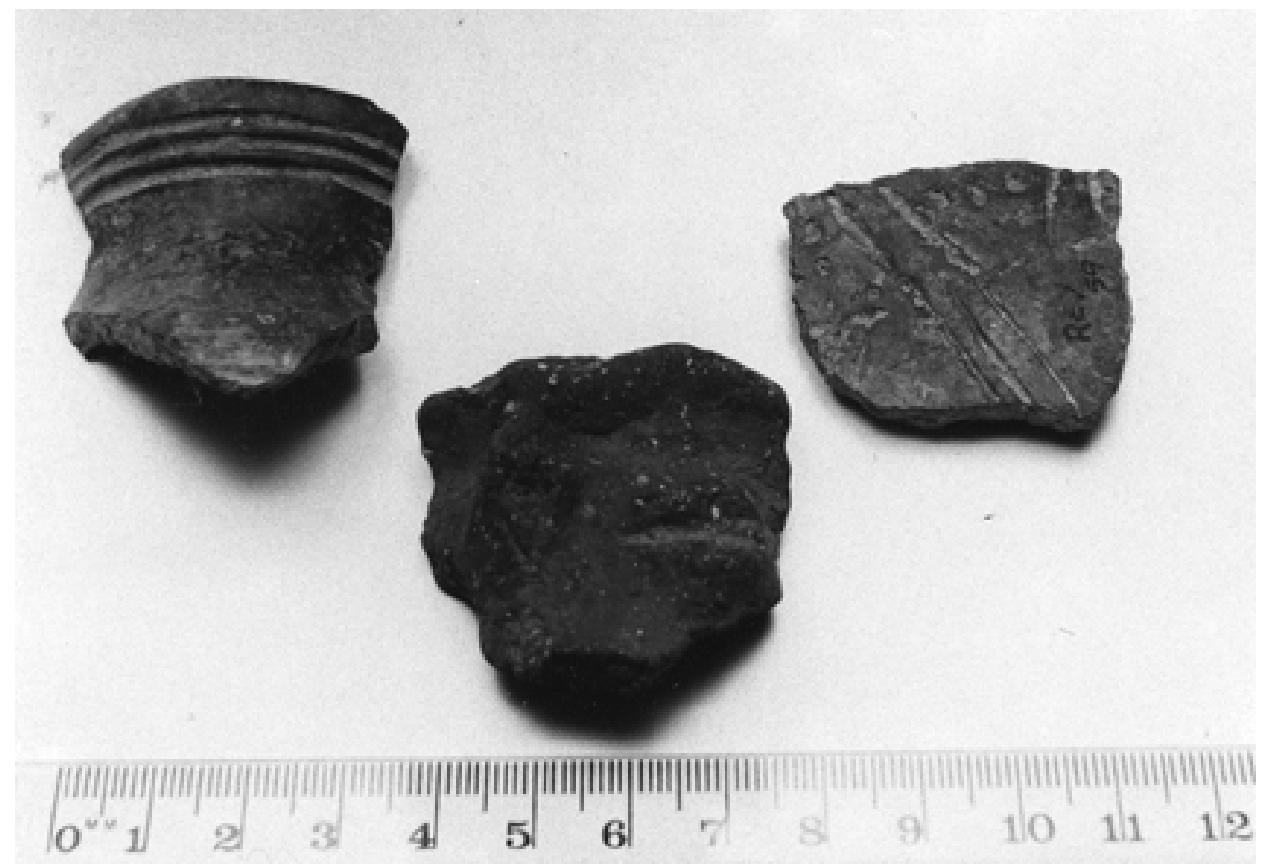

Figura 4. Cerámica de San Pablo de Reyes.

San Pablo de Reyes pottery.

La alfarería, en general muy erosionada, corresponde a los tipos: Naranja Alisado, Gris Alisado, Amarillento Alisado, Marrón Alisado, Marrón Amarillento Ordinario y Rojizo Alisado. Algunos fragmentos presentan cobertura roja muy desleída. Un fragmento Rojizo Alisado presenta corrugamiento y solamente dos fragmentos pequeños son incisos alisados del tipo San Francisco aunque de manufactura desprolija. Uno de ellos es amarillento de textura media con inclusiones de litoclastos sedimentarios subangulosos de granulometría no uniforme, se observan algunos fragmentos grandes de areniscas (blancuzcas) y aparente agregado de tiesto molido. El otro es Gris Claro de pasta gris negra pareja, de aspecto terroso, con inclusiones grises más claras, redondeadas y no uniformes que podrían corresponder a tiesto molido.

Como caracterización general de las pastas de Lozano, podemos decir que una clase de pastas está integrada por los fragmentos Marrones Ordinarios y Marrones Lisos con abundante cuarzo y cuarcitas de granulometría grande y muy grande. Pero también pueden tener muy pocas de estas inclusiones en una matriz fina marrón o gris. Asimismo, hay Marrones Alisados de paredes gruesas con abundante cuarzo y tiesto molido. Los otros fragmen- tos tienen pastas gruesas con abundantes litoclastos sedimentarios y metamórficos tabulares y subredondeados, inclusiones de cuarzo y cuarcitas. Estas pastas son similares a las ordinarias del tardío del sector meridional y oriental de la quebrada de Humahuaca.

En Lozano las formas corresponden fundamentalmente a ollas medianas de bordes evertidos con asas en arco de sección rectangular, cuencos o tazones alisados de paredes bastante delgadas y ollas de tipo tubular, representadas por fragmentos rojizos y marrones amarillentos ordinarios de paredes muy gruesas con bordes directos de labio plano, a veces con engrosamiento interno (Figura 5). Además del material cerámico, se recuperaron tres puntas de proyectil de obsidiana triangulares con pedúnculo de 2 y $2,50 \mathrm{~cm}$ de largo. El resto del material lítico corresponde a fragmentos de manos de mortero.

San Pablo de Reyes y Lozano presentan un patrón de emplazamiento muy similar, ambos son monticulares y están instalados sobre terrazas del río Grande, sobre la margen izquierda del mismo y en las cercanías de la desembocadura de ríos subsidiarios; distan entre sí $10 \mathrm{~km}$. Geomorfológicamente, la zona corresponde al valle extendido que 


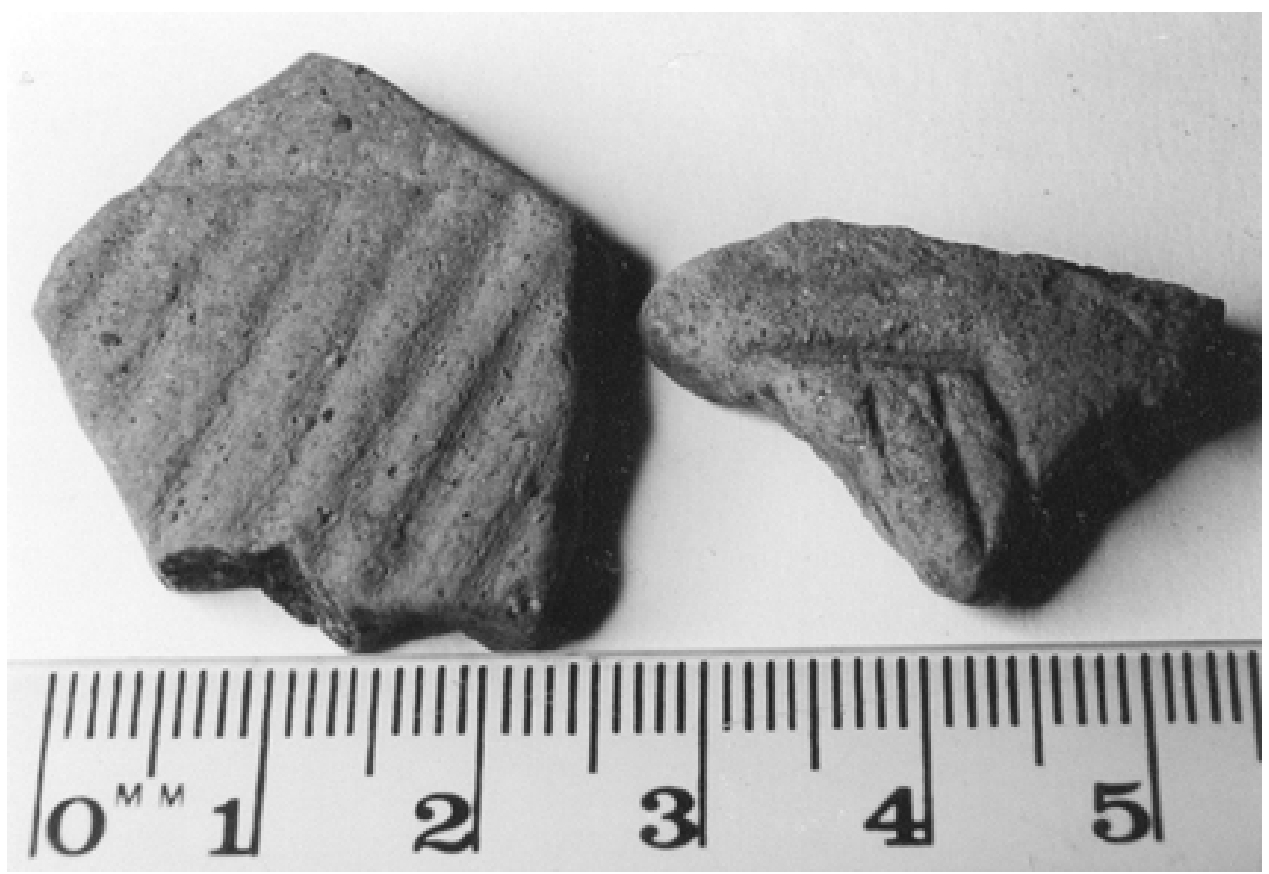

Figura 5. Cerámica de Lozano (Loz-1).

Lozano (Loz-1) pottery.

forma el río Grande al norte de la ciudad de San Salvador de Jujuy. Estos valles presentan amplias y fértiles superficies aptas para el cultivo, que sin duda se relacionan con la economía y funcionalidad de las instalaciones humanas estudiadas. Desde el punto de vista ambiental, la zona corresponde a la formación de yungas occidentales o empobrecidas y al piso ecológico que Brown y Ramadori (1989) denominan selva de transición y otros autores selva de pedemonte. Las especies características son: ceibo (Erytrina falcata); tipa blanca (Tipuana tipa); lapacho (Tabebuia avellanedae) y yuchán (Chorisia insignis); también hay epífitas y parásitas. Actualmente la acción antrópica es muy intensa y gran parte de esta cubierta ha desaparecido.

\section{Trigo Pampa}

El sitio se encuentra emplazado en los valles orientales, sobre una terraza cuaternaria del arroyo Trigo Pampa, que conjuntamente con el Ocloyas y Paihuaico forman el río Catres, que luego se denomina Caulario, Candelaria, Ledesma y con este nombre desagua en el río San Francisco. En esta zona el valle se ensancha, favoreciendo la aparición de una superficie aplanada, apta para el culti- vo. La formación fitogeográfica corresponde a las yungas, en el piso de la selva montana y su transición al bosque montano. El yacimiento no presenta estructuras sobre la superficie, distinguiéndose como una suave elevación. Prácticamente sobre el mismo se encuentra instalada una vivienda actual y un corte que se efectuó para nivelar el piso del patio dejó expuesto un perfil con material cultural. La alteración producida impide conocer la superficie original del suelo, pero de acuerdo a la zona no alterada que lo rodea, estimamos que la capa fértil se inicia a los 0,60 $\mathrm{m}$ de profundidad y tiene una potencia de $0,40 \mathrm{~m}$. Se recuperaron solamente fragmentos cerámicos, aunque es importante destacar en las adyacencias la presencia de un mortero "de tacitas" en el que se distinguen siete concavidades mayores y otras más pequeñas y planas que parecen ser naturales. Asimismo consignamos que el dueño de la vivienda nos mostró dos hachas de mano subcilíndricas, con cuello, que relata haber extraído del mismo lugar.

La alfarería es poco variada y en su totalidad alisada. Se han podido establecer los siguientes tipos: Rojizo Ordinario de paredes y pastas gruesas con agregado de arena (como el Castaño Alisado de Volcán); Amarillento Ordinario con barbotina 
(pasta similar al Rojo Ordinario de Volcán); Castaño Amarillento Alisado, de pastas gruesas de aspecto negro terroso con escasas inclusiones no uniformes de litoclastos angulosos más claros; Amarillento Alisado de pasta similar pero más fina (un fragmento de probable botellón y otro de vasija restringida grande de cuello largo y recto con borde levemente evertido); Gris Claro Ordinario, de paredes medias y pastas gruesas con abundantes litoclastos de filitas (también presentes en San Pablo de Reyes); Castaño Rojizo Alisado (similar al Rojo Alisado de Volcán) correspondiente a fragmentos de pucos y con pastas como las de algunos grises pulidos incisos de Volcán. Los únicos fragmentos decorados corresponden a una escudilla marrón grisácea alisada con chevrones escalonados del tipo S.F. Alisado Inciso de pasta similar a la de los Amarillentos Alisados presente en algunos Grises Pulidos Incisos de Volcán. Algunos fragmentos presentan rastros de cobertura rojo naranja (Figura 6).

\section{Tipos de Emplazamiento y Contextos Cerámicos}

Los asentamientos citados presentan características diferentes en su emplazamiento, respecto de los hasta ahora conocidos en quebrada de Humahuaca y laterales (Tabla 2). Estos últimos se encuentran mayoritariamente instalados en franjas ecotonales, extendidas entre la puna y las cabeceras de quebradas subsidiarias a la de Humahuaca, alrededor de los 3.000 msnm (Estancia Grande, Antumpa, Alfarcito), correspondiendo al primer tipo de los planteados por Tarragó. Por otro lado, los asentamientos San Francisco del área nuclear ubicados en las adyacencias del río homónimo se encuentran por debajo de los $1.000 \mathrm{msnm}$. En cambio, debemos destacar que los situados en los valles presentan similitudes entre sí: San Pablo de Reyes, Lozano y Trigo Pampa se encuentran instalados sobre fértiles terrazas fluviales que favorecen la producción agrícola, lo cual consideramos pudo ser la razón que impulsó la radicación de estos grupos.

Con relación al sitio ubicado por debajo del Pukara de Volcán, su emplazamiento muestra características distintivas. Se encuentra sobre una topografía elevada sobre el fondo de valle, a 2.080 msnm, en un ámbito de prepuna, pero más favorecido por los vientos húmedos del sudeste, respecto al sector central y norte de la quebrada. Esto genera mayor cantidad de lluvias y la presencia de neblinas durante todo el año, que permiten el

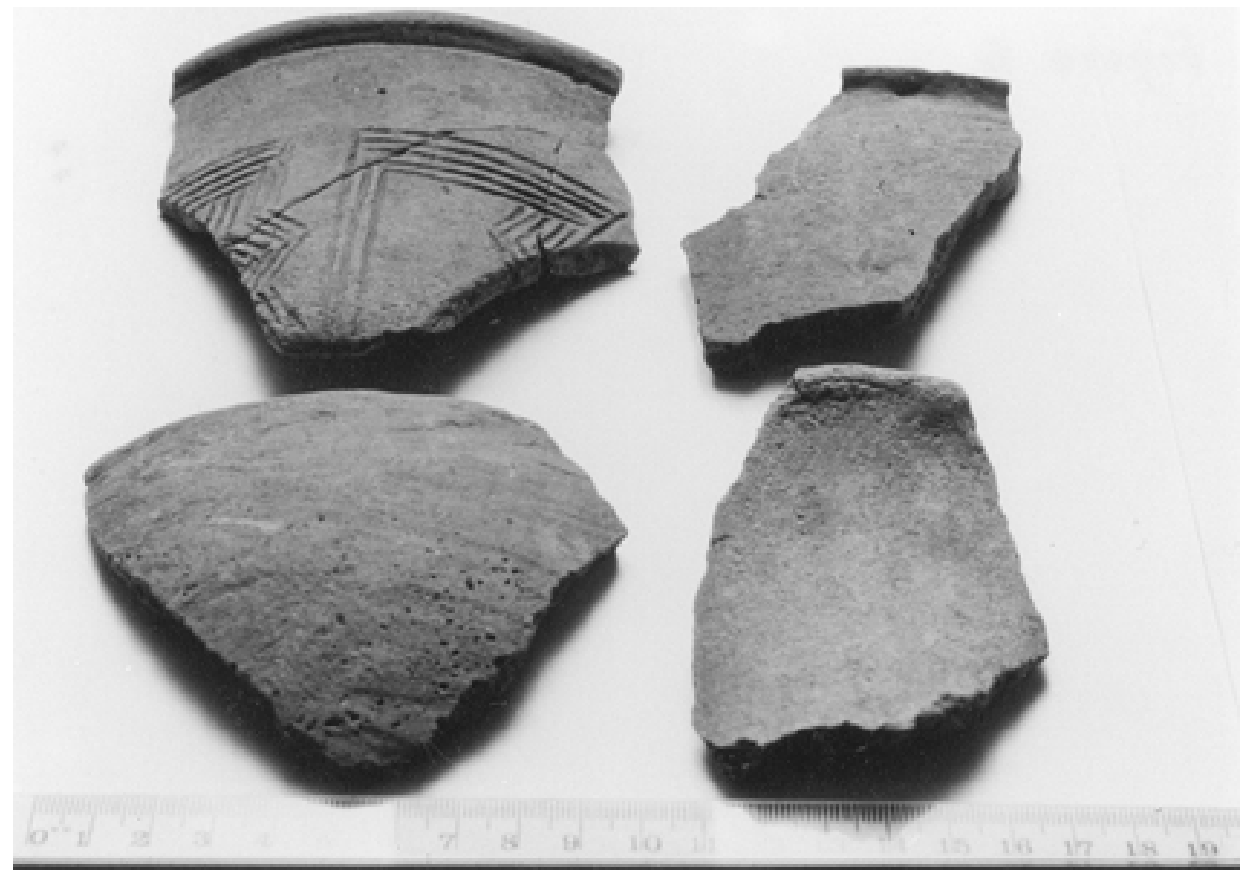

Figura 6. Cerámica de Trigo Pampa.

Trigo Pampa pottery. 
Tabla 2. Características del emplazamiento y tipos de cerámica de los sitios el Volcán, Trigo Pampa, Lozano y San Pablo de Reyes.

Placement conditions and pottery types from the Volcán, Trigo Pampa, Lozano, and San Pablo de Reyes sites.

\begin{tabular}{|c|c|c|c|c|c|}
\hline Sitio & Tipo & Altura & Ambiente & Ubicación & Cerámica \\
\hline Volcán & $\begin{array}{l}\text { No se puede } \\
\text { definir }\end{array}$ & $2.080 \mathrm{msnm}$ & Quebrada Prepuna & $\begin{array}{l}\text { En cono volcado. } \\
\text { Altura sobre fondo } \\
\text { de valle: } 150 \mathrm{~m}\end{array}$ & $\begin{array}{l}\text { S.F. Gris Pulido Inciso } \\
\text { S.F. Ordinario } \\
\text { S.F. Pulido Negro Inciso } \\
\text { S.F. Pulido Rojo s/Ante } \\
\text { S.F. Pulido Bicolor }\end{array}$ \\
\hline Trigo Pampa & Montículo & $1.600 \mathrm{msnm}$ & $\begin{array}{l}\text { Valles orientales } \\
\text { yungas (entre } \\
\text { selva y bosque } \\
\text { montano) }\end{array}$ & Terraza fluvial & $\begin{array}{l}\text { Rojizo Ordinario } \\
\text { Amarillento Ordinario } \\
\text { Castaño Alisado } \\
\text { Amarillento Alisado } \\
\text { Gris Claro Ordinario } \\
\text { Castaño Rojizo Alisado } \\
\text { S.F. Alisado Inciso }\end{array}$ \\
\hline Lozano & Montículo & $1.450 \mathrm{msnm}$ & $\begin{array}{l}\text { Valles } \\
\text { Meridionales } \\
\text { yungas (selva de } \\
\text { transición) }\end{array}$ & Terraza fluvial & $\begin{array}{l}\text { Naranja Alisado } \\
\text { Gris Alisado } \\
\text { Amarillento Alisado } \\
\text { Marrón Alisado } \\
\text { Marrón Ordinario } \\
\text { Rojizo Alisado } \\
\text { S.F. Alisado Inciso }\end{array}$ \\
\hline $\begin{array}{c}\text { San Pablo de } \\
\text { Reyes }\end{array}$ & Montículo & $1.400 \mathrm{msnm}$ & $\begin{array}{l}\text { Valles } \\
\text { meridionales } \\
\text { yungas (selva de } \\
\text { transición) }\end{array}$ & Terraza fluvial & $\begin{array}{l}\text { Gris Claro Ordinario } \\
\text { Castaño Amarillo Alisado o } \\
\text { Rojizo Micáceo } \\
\text { Marrón Ordinario } \\
\text { Marrón Alisado } \\
\text { S.F. Pulido Gris Inciso } \\
\text { Negro Inciso }\end{array}$ \\
\hline
\end{tabular}

desarrollo de abundantes pastizales en los faldeos occidentales, muy aptos para el pastoreo de camélidos ${ }^{4}$.

De todos los sitios estudiados, Volcán es el que presenta el componente San Francisco más abundante, variado y definido. San Pablo de Reyes se diferencia por la presencia de modelados con tiras aplicadas con incisiones que forma parte del conjunto de fragmentos muy micáceos de pastas con agregado de arena gruesa. Pero, a su vez, comparte fundamentalmente con Trigo Pampa y Lozano las alfarerías Amarillentas y Marrones Alisadas con pastas similares y está presente el S.F. Pulido Gris Inciso y Negro Inciso, ampliamente representados en el contexto alfarero de Volcán. Podemos decir que San Pablo de Reyes también presenta componentes claros San Francisco. Sin embargo, la cerámica con mica es muy poco frecuente en el S.F.
Ordinario (Dougherty 1977), así como las caras modeladas con tiras agregadas con incisiones que corresponden a unos pocos fragmentos recuperados por Nordenskiöld y que han permitido postular un cierto "aire de familia" entre el Candelaria I y el San Francisco. Cabe preguntarnos si en San Pablo de Reyes, junto con elementos San Francisco, no están también representados elementos de otra tradición temprana, también de origen oriental, ampliamente representada en las alfarerías de la Fase I de Tafí y que no corresponderían a elementos alóctonos sino a vasijas de manufactura local integradas a la tradición Tafí (Cremonte 1997; Núñez Regueiro y Azcárate 1996). Si bien no contamos con dataciones cronométricas para San $\mathrm{Pa}$ blo de Reyes, con base en la cerámica puede plantearse que esta ocupación podría ser contemporánea a la de Volcán. 
Trigo Pampa y Lozano presentan una situación diferente. En ambos sitios la cerámica incisa San Francisco está apenas representada, las superficies son alisadas, los trazos más desprolijos se ejecutaron sobre paredes blandas y corresponden a vasijas abiertas de paredes delgadas y frágiles que se corresponderían con las del tipo Las Capillas Gris Inciso. A su vez, el fragmento corrugado de Lozano es análogo al que ilustra Dougherty procedente de Las Capillas, así como la presencia de barbotina que muestran algunos fragmentos de Lozano. Trigo Pampa y Lozano podrían ser ocupaciones más tardías que las de San Pablo de Reyes y Volcán, probablemente contemporáneas con las de Las Capillas y Palpalá, tentativamente ubicadas entre los 300 a 600 d.C. (Dougherty et al. 1984). Trigo Pampa pudo ser un asentamiento más tardío y marginal con respecto a los conocidos para el área del río San Francisco, en tanto Lozano presenta, a su vez, elementos que lo relacionan con otros sitios de la quebrada de Humahuaca, reflejados en los fragmentos de grandes ollas tubulares.

Con relación a otros sitios agropastoriles del Formativo de la quebrada de Humahuaca, en los cuatro sitios que estamos comentando no se registraron las cerámicas marrones pulidas en líneas, los pucos con interior negro ni el tipo Alfarcito Gris pulido, asociaciones que se reiteran tanto en Estancia Grande como en Alfarcito (Olivera y Palma 1997; Zaburlin et al. 1996) y al que debemos agregar Til 20 (Menconça et al. 1991). En cuanto a las grandes ollas tubulares registradas en estos sitios, solamente en Lozano se recuperaron fragmentos asignables a las mismas. Estas ollas tubulares son adscriptas al momento agrícola más temprano de la quebrada de Humahuaca (Tarragó y Albeck 1997). En cuanto a la presencia de vasijas pintadas monocromas rojas, en San Pablo de Reyes, Trigo Pampa y Lozano, recuperamos algunos fragmentos ordinarios con rastros de estas coberturas, muy desleídas y que corresponderían a vasijas medianas inflexas de cuellos evertidos. Por otro lado, en ninguno de nuestros sitios registramos fragmentos tricolores o pintados en Negro sobre Rojo con líneas gruesas paralelas y quebradas como en el sitio Til 22 de Tilcara (Rivolta y Albeck 1992; Tarragó y Albeck 1997), si bien corresponderían a un momento posterior según los fechados conocidos en asociación con las mismas ${ }^{5}$.

\section{Discusión}

Hasta hace pocos años, en la provincia de Jujuy se conocían asentamientos formativos en quebradas subsidiarias a la quebrada de Humahuaca, sobre el eje de la quebrada, en la puna y las pertenecientes a la cuenca del río San Francisco. Los mismos presentaban características definidas en su patrón de instalación, en sus artefactos y contextos relacionados con el medio ambiente en que estaban emplazados ${ }^{6}$. Así se establecía una diferenciación bastante clara entre los asentamientos propios de las tierras altas y el ámbito de prepuna respecto de aquellos que correspondían a las Selvas Occidentales de las tierras bajas. La aparición de alfarería de la tradición San Francisco en sitios de quebrada o cercanos a quebrada como Alfarcito (Til 41), pero en baja densidad, indica ser alóctona según el estado actual de las investigaciones y su presencia explicable por procesos de complementariedad $\mathrm{y} / \mathrm{o}$ reciprocidad.

El hallazgo de una ocupación permanente San Francisco en el ámbito de la quebrada de Humahuaca, por debajo de la instalación tardía del Pukara de Volcán (Cremonte y Garay de Fumagalli 1995, 1997), permitió comprobar que grupos provenientes de la cuenca del río San Francisco habían ocupado ecosistemas totalmente diferentes a aquellos en los cuales estaban radicados. Dicha instalación, fechada a principios de la era cristiana y que presenta un conjunto alfarero propio de las sociedades San Francisco pero de fabricación local, pudo tener como objetivo la ganadería de camélidos (Myriam Tarragó, comunicación personal) en un ambiente que ofrece condiciones óptimas para la misma. Asimismo, no podemos dejar de considerar que esta instalación pudo favorecer interacciones de corta y larga distancia con otras sociedades de la quebrada y subsidiarias como probablemente Estancia Grande y sitios de la quebrada de León, de las cabeceras de la quebrada del Toro como Las Cuevas y oasis de la puna de Atacama (Llagostera y Costa Junqueira 1999). Las evidencias obtenidas acerca de asentamientos formativos en los valles orientales y en el valle de Jujuy, en instalaciones permanentes, brindan nueva información respecto a la ocupación territorial por parte de sociedades agropastoriles tempranas, en zonas hasta ahora desconocidas, y nos permiten efectuar comparaciones con los sitios conocidos en la quebrada de Humahuaca y subsidiarias. 
Si comparamos los sitios de Trigo Pampa, Lozano y San Pablo de Reyes entre sí y con el asentamiento temprano de Volcán, notaremos similitudes y diferencias entre los nombrados y respecto a los otros sitios formativos ya estudiados en la quebrada. El primer aspecto significativo que debemos destacar, es que los sitios ubicados en los valles sudorientales de Jujuy y el de Volcán comparten alfarerías asignables a la tradición San Francisco, por lo que se diferencian de los sitios de la zona central y norte de la quebrada y adyacencias. En cuanto a las diferencias, la más significativa es que los conjuntos de Volcán muestran un componente San Francisco definido y claro, representado por el tipo S.F. Pulido con decoración incisa lineal gruesa y punteada, cerámicas castañas o beige pulidas de paredes gruesas del S.F. Monocromo Pulido y en baja frecuencia el S.F. Pulido Bicolor, con fragmentos pintados en morado sobre amarillo. El tratamiento y acabado de superficie de los fragmentos grises pulidos y pintados de Volcán, así como la petrografía de sus pastas, son análogos a los hallados en San Francisco, pero los análisis químicos por fluorescencia de rayos X (Cremonte y Solís 1998) muestran que la manufactura es local, lo cual indicaría que la ocupación temprana de referencia corresponde a grupos San Francisco instalados sobre la quebrada de Humahuaca. En tanto, San Pablo de Reyes presenta también grises pulidos incisos que lo relacionan con un componente San Francisco definido y elaborado, pero se distingue por un conjunto de fragmentos micáceos, algunos incisos y modelados que no están representados en los otros sitios. Trigo Pampa y Lozano muestran algunos fragmentos San Francisco, pero como una manifestación pobre y marginal de esa tradición. En Lozano se destacan las ollas tubulares como en sitios ya comentados de la quebrada. Todos los sitios comparten en mayor o menor medida el mismo tipo de vasijas ordinarias y alisadas, así como la manufactura de sus pastas.

Por lo dicho anteriormente, las similitudes y diferencias encontradas entre los conjuntos del sur de la quebrada de Humahuaca y valles sudorientales, en cuanto a emplazamiento y contextos alfareros, nos llevan a plantear interrogantes sobre las formas de ocupación territorial que se desarrollaron en este sector durante el Formativo. Volcán, emplazado en un medio ambiente de prepuna, parece demostrar que las sociedades San Francisco tuvieron la fuerza y capacidad como para destacar grupos que ocuparon territorios en un ambiente totalmente diferente al que les era propio, o sea el de las Selvas Occidentales.

En cuanto a San Pablo de Reyes y sitios estudiados por otros autores como Bajo La Viña (Kulemeyer et al. 1997), consideramos que representan extensiones territoriales de las sociedades San Francisco, instaladas en los valles húmedos de San Salvador de Jujuy y aledaños. Esta continuidad en la ocupación hacia el occidente estaría representada asimismo en Palpalá (Dougherty 1974a). Dichas ocupaciones no diferirían sustancialmente de las propias del área nuclear, en cuanto a formas de instalación y obtención de recursos, fundados principalmente en la producción agrícola. Por otro lado, Los Blancos (Armonía y Laguna 2000) y Los Perales (Dougherty 1975) ubicados sobre el valle de Jujuy, parecen haber sido asentamientos San Francisco dedicados a la explotación de madera, como lo demuestra la predominancia de hachas líticas en sus conjuntos ergológicos.

Trigo Pampa también podría corresponder a un asentamiento marginal y probablemente más tardío, respecto a los núcleos originales instalados en el valle del río San Francisco, ubicado en este caso en los valles orientales, como ocurre con Las Capillas (Dougherty et al. 1984).

Lozano se manifiesta como un sitio del sur de la quebrada de Humahuaca que no puede ser caracterizado claramente como San Francisco, debido a la escasa presencia de cerámica decorada, característica de esta tradición y por presentar fragmentos de vasijas que se reiteran en otros sitios de dicha quebrada, como las ollas tubulares. Si bien se rescataron dos fragmentos incisos alisados del tipo San Francisco, su baja representatividad indica que pueden ser producto de procesos de interacción.

Del análisis planteado en este trabajo, surgen como hipótesis que: (a) El asentamiento San Francisco de Volcán indica que hacia inicios de la era las sociedades que habitaban el valle del río San Francisco se hallaban en expansión y que tal expansión pudo haber impulsado procesos de interacción con otras sociedades instaladas en ambientes diferentes, poseedoras de recursos que habrían alentado el establecimiento de redes de intercambio. Volcán pudo ser el sitio propicio para instalar una "base" permanente que favoreciera el acceso tanto a otros asentamientos de la quebrada de Humahuaca como del borde de puna salteño (que- 
brada del Toro) y del altiplano, por poseer extensos pastizales que permitirían el sostenimiento de una actividad ganadera, valiosa como recurso alimentario y de transporte; (b) La diversidad en las formas de ocupación territorial y control de recursos que muestran los sitios estudiados, indica diferentes estrategias de exploración y explotación de territorios. Esto correspondería a un cierto grado de centralidad política e ideológica representada a través de un estilo cerámico emblemático.

Por lo expuesto anteriormente, concluimos que los sitios formativos de los valles sudorientales que hemos presentado muestran en todos los casos relación con las sociedades San Francisco. Esta evidencia indica: (1) que dichas sociedades tuvieron una expansión territorial y una diversidad en los tipos de ocupación y explotación de recursos mucho mayor que la hasta ahora considerada: (2) que explotaron recursos a distancia de la cuenca del río San Francisco en medio ambientes distintos a los que les eran propios; (3) que participaron en procesos de interacción a corta y larga distancia.
Si a esto sumamos el grado de desarrollo tecnológico y estilístico de la cerámica, consideramos válido replantear, con respecto al modelo formulado por Dougherty, el nivel de desarrollo sociopolítico que pudieron haber alcanzado las entidades socioculturales caracterizadas arqueológicamente como tradición San Francisco, que probablemente trascendieron el de meros núcleos aldeanos restringidos al área del río homónimo, tal como tradicionalmente se les ha adjudicado. Consideramos que la tradición San Francisco debe ser incluida en las discusiones actuales sobre la complejidad creciente que están mostrando las sociedades del Formativo (Núñez Regueiro y Tartusi 1999).

Agradecimientos: Las investigaciones fueron financiadas mediante subsidios de la SECTER (UNJU) y PIA 7.155/97 de CONICET. Deseamos agradecer la colaboración de los alumnos Gabriela Molina y Pablo Trenque en los trabajos de campo y registro de los materiales. Nuestro reconocimiento a la familia Bárcena por su constante apoyo.

\section{Referencias Citadas}

Armonía, S. y L.R. Laguna

2000 Los Blancos: un nuevo sitio arqueológico en los alrededores de la ciudad de San Salvador de Jujuy. Ponencia presentada en VI Jornadas de Investigación en Humanidades y Ciencias Sociales, Jujuy.

Boman, E.

1908 Antiquités de l Région Andine de la Republique Argentina et du Désert d'Atacama. Tome II. Imprimerie Nationale, Paris.

Brockington, D.L., D.M. Pereira H., R.A. Sanzetenea R. y M. Muñoz

1995 Estudios arqueológicos del Período Formativo en el Sur-Este de Cochabamba. Cuadernos de Investigación. Serie Arqueológica 8: 1-180.

Brown, A. y E. Ramadori

1989 Patrón de distribución, diversidad y características ecológicas de especies arbóreas de las selvas y bosques montanos del noroeste de la Argentina. Actas VI Congreso Forestal Tomo 1: 177-181. Universidad Nacional de Tucumán, Tucumán.

Cardich, A.

1980 El fenómeno de las fluctuaciones de los límites superiores del cultivo en los Andes. Su importancia. Relaciones XIV, $\mathrm{N}^{\mathrm{o}}$ 1: 7-31.

Cremonte, M.B.

1997 Investigaciones arqueológicas en la Quebrada de La Ciénega (Dto. Tafí, Tucumán). Tesis Doctoral, Facultad de Ciencias Naturales y Museo, Universidad Nacional de La Plata.
Cremonte, M.B. y M. Garay de Fumagalli

1995 Estado actual de las investigaciones arqueológicas en el sector meridional de la Quebrada de Humahuaca y su borde oriental. Actas I Congreso en Investigación en Ciencias Sociales: 379-393. Universidad Nacional de Tucumán, Tucumán.

Cremonte, M.B. y M. Garay de Fumagalli

1997 El enclave de Volcán en las vinculaciones transversales del Valle de Humahuaca. (Noroeste de Argentina, Jujuy). En Intercambio y Comercio entre Costa, Andes y Selva. Arqueología y Etnohistoria de Sudamérica, editado por F. Cárdenas-Arroyo y T. Bray, pp. 297-319. Universidad de Los Andes, Bogotá.

Cremonte, M.B. y M. Garay de Fumagalli

1999 Una ocupación Formativa en el sur de la quebrada de Humahuaca. Actas XIII Congreso Nacional de Arqueología Argentina, en prensa.

Cremonte, M.B. y N. Solís.

1998 La cerámica del Pucara de Volcán: Variaciones locales y evidencias de interacción. Los Desarrollos Locales y sus Territorios. Arqueología del NOA y sur de Bolivia, compilado por M.B. Cremonte, pp. 155-196. Universidad Nacional de Jujuy, Jujuy.

Dougherty, B.

1974a Informe preliminar sobre un nuevo yacimiento arqueológico en Palpalá. Provincia de Jujuy. Su ubicación dentro del Complejo San Francisco. Relaciones VIII: 135-152.

Dougherty, B.

1974b Análisis de la variación medioambiental en la subregión arqueológica de San Francisco (Región Selvas Occidentales - subárea del NO argentino) Etnía 20: 1-11. 
Dougherty, B.

1975 Nuevos aportes al conocimiento del Complejo Arqueológico San Francisco (Sector septentrional de la Región de las Selvas Occidentales). Tesis Doctoral, Universidad Nacional de La Plata, La Plata.

Dougherty, B.

1977 Análisis de la variación cerámica en el Complejo San Francisco. Obra de Centenario del Museo de La Plata Tomo II: 237-252. Facultad de Ciencias Naturales y Museo, Universidad Nacional de La Plata, La Plata.

Dougherty, B., C. de Feo y A.M. Fernández 1999 El Complejo Arqueológico San Francisco: El Sitio El Fuerte. Cuestiones de cronología. La mitad Verde del Mundo Andino. Estado Actual de las Investigaciones Arqueológicas en la Vertiente Oriental de los Andes y las Tierras Bajas de Bolivia y Argentina, en prensa.

Dougherty, B., A.M. Fernández y E. Zagaglia

1984 Arqueología del Río Capillas (Dto. Capital, Prov. de Jujuy). Revista del Museo de La Plata, n.s. Tomo VIII, Antrop. 58: 197-221.

Fernández Distel, A.

1988 Ubicación temporal a través de nuevos fechados radiocarbónicos del Complejo Cultural San Francisco. Paleoetnológica 5: 191-204.

Fernández Distel, A.

1994 Noticia sobre el sitio arqueológico de Abra de Los Morteros y otros lugares de valor prehistórico en la región de Santa Bárbara (Jujuy, Rep. Argentina). De Costa a Selva: Producción e Intercambio entre los Pueblos Agroalfareros de los Andes Centro-Sur, editado por M.A. Albeck, pp. 255-300. Instituto Interdisciplinario Tilcara, Universidad Nacional de Buenos Aires, Tilcara.

Garay de Fumagalli, M.

1996 Noticia preliminar acerca de la presencia de un yacimiento formativo en San Pablo de Reyes. Prov. de Jujuy. En XXV Aniversario Museo Arqueológico "Dr Eduardo Casanova”, pp. 53-62. Instituto Interdisciplinario Tilcara, Universidad Nacional de Buenos Aires, Tilcara.

Garay de Fumagalli, M. y M.B. Cremonte

1999 Una ocupación temprana en el Pukara de Volcán. Ponencia presentada en el XIII Congreso Nacional de Arqueología Argentina, Córdoba.

González, A.R.

1963 Las tradiciones alfareras del período temprano del N.O. Argentino y sus relaciones con las áreas aledañas. Actas Congreso Internacional de Arqueología San Pedro de Atacama: 49-65. Anales de la Universidad del Norte 2, Antofagasta.

Hernández Llosas, M.L., S. Renard y M.M. Podestá 1985 Antumpa (Dto. Humahuaca, Prov. de Jujuy): Prospección, Excavación Exploratoria y Fechado Radiocarbónico. Cuadernos del Instituto Nacional de Antropología: 525-531. Heredia, O.

1975 Investigaciones arqueológicas en el sector meridional de las Selvas Occidentales. Revista del Instituto de Antropología 5: 73-132.

Kulemeyer, J., M. Echenique y L.R. Laguna 1997 La cerámica con decoración incisa y modelada de Bajo La Viña, San Salvador de Jujuy (Argentina). Cuadernos 9: 87-110.
Llagostera, A. y M.A. Costa Junqueira

1999 San Pedro de Atacama antes del 1000 AD. Actas XII Congreso Nacional de Arqueología Argentina, editado por Cristina Diez Marín, Tomo 1: 92-101. Universidad Nacional de La Plata, La Plata.

Madrazo, G.

1969 Reapertura de las investigaciones en Alfarcito. Monografía $N^{\circ} 4$. Museo Etnográfico Municipal Olavaria, Olavaria.

Menconça, O., A. Bordach, M. Ruiz y M.B. Cremonte. 1991 Nuevas evidencias del Período Agroalfarero Temprano en la Quebrada de Humahuaca. Los hallazgos del sitio Til 20. Comechingonia 7: 31-45

Nordenskiöld, E.

1903 Pracolumbische Wohn-un begrabnisplatze andder sudWestgrenze von Chaco. Kgl. sveska Vetenskaps Akademiens Handlingar 36. Stockholm.

Núñez Atencio, L. y T. Dillehay

1995 Movilidad Giratoria, Armonía Social y Desarrollo en los Andes Meridionales. Patrones de Tráfico e Interacción Económica. Ensayo. Universidad Católica del Norte, Antofagasta.

Núñez Regueiro, V. y J. Azcárate

1996 Investigaciones arqueológicas en El Mollar, Dto. Tafí del Valle, Pcia de Tucumán. Actas y Memorias del XI Congreso Nacional de Arqueología Argentina. Revista del Museo de Historia Natural de San Rafael XXV, $\mathrm{N}^{\mathrm{o}}$ 1/2: 83-97.

Núñez Regueiro, V. y M. Tartusi

1999 Análisis de la problemática del estudio de las sociedades agropastoriles de Area Centro Sur Andina. Actas XII Congreso Nacional de Arqueología Argentina Tomo 1: 107112. Ed. Cristina Diez Marín, Universidad Nacional de La Plata, La Plata.

Olivera, D. y J. Palma

1992 Hacia la contrastación de un modelo arqueológico para el Formativo regional de Humahuaca: El caso de estancia Grande. Cuadernos del Instituto Nacional de Antropología y Pensamiento Latinoamericano 14: 237-259.

Olivera, D. y J. Palma

1997 Cronología y registro arqueológico en el Formativo Temprano en la región Humahuaca. Avances en Arqueología 3: 77-99.

Ortiz, M.G.

1997 Arqueología del sector sureste de las tierras bajas Provincia Jujuy. Informe CONICET, Argentina.

Ortiz, M.G.

2000 Nuevos avances en torno a las investigaciones arqueológicas en las Tierras Bajas de Jujuy (Subárea San Francisco). Cuadernos (FHYCS-UNJu), en prensa.

Pérez Gollán, J.

1973 Arqueología de las culturas agroalfareras de la Quebrada de Humahuaca (Provincia de Jujuy, Rep. Argentina). América Indígena. Vol XXXIII, Nº 3: 667-679.

Rivolta, C. y M.E. Albeck

1992 Los asentamientos tempranos en la localidad de Tilcara: Sjuj Til22. Provincia de Jujuy. Cuadernos 3: 86-93.

Serrano, F.

1962 Investigaciones Arqueológicas en el Valle del Río San Francisco (Prov. de Jujuy). Imprenta Salesianos, Salta. 
Stuiver, M. y P.J. Reimer

1993 Radiocarbon Calibration Program. Radiocarbon 35: 215-230.

Tarragó, M.

1992 El Formativo y el surgimiento de la complejidad social en el Noroeste. En Formativo Sudamericano. Una Reevaluación. Homenaje a A.R. González y B.J. Meggers, editado por P. Ledergerber-Crespo, pp. 302-313. Abya-Yala, Quito.
Tarragó, M. y M.E. Albeck

1997 Fechados radiocarbónicos para el sector medio de la Quebrada. Avances en Arqueología 3: 101-129

Zaburlin, M.A., H. Mamani, S. Dip y M.E. Albeck 1996 SJujTil-41: Alfarcito: Variaciones sobre un clásico. Actas XI Congreso Nacional de Arqueología Argentina. Revista del Museo de Historia Natural de San Rafael XXV, $\mathrm{N}^{\mathrm{o}}$ 1/2: 71-86.

\section{Notas}

1 El área nuclear de la tradición San Francisco abarca... "aproximadamente el ámbito determinado por las últimas estribaciones orientales de la porción septentrional de las sierras subandinas del sur. Se trata de una serie de cordones montañosos (...) que de $\mathrm{O}$ a $\mathrm{E}$ reciben los nombres de Zenta, Calilegua, Sta. Bárbara, Centinela, Maíz Gordo y Lumbrera (...). Dos cauces importantes corren entre las sierras (...) el río San Francisco, nacido de las aguas del Grande de San Pedro y el Lavayén, este marca aproximadamente el eje principal de la subregión homónima” (Dougherty 1975: 6). Este sector corresponde a la porción septentrional de la subárea de las Selvas Occidentales definidas por Rex González (1963).

2 El modelo planteado por Tarragó (1992) se incorpora a los fines de presentar una caracterización de los tipos de emplazamiento de los sitios correspondientes al Formativo.

3 Las evidencias arqueológicas que corroboran el uso de estas vías naturales de comunicación son: -Para la cuenca del río Grande de San Pedro-valle de Jujuy: el sitio Palpalá (PA II) (Dougherty 1974a), el sitio Bajo La Viña (Kulemeyer et al. 1997), el sitio Los Blancos (Armonía y Laguna 2000). -Para la cuenca río Negro-río CapillasCucho: el sitio Las Capillas, Antigal de Tacanas, Potrero de Chañi, Campo del Barro y Tunalito (Dougherty et al.1984). -Para la cuenca río Ledesma-Corral de Piedra: el sitio Trigo Pampa.

4 Carecemos de los datos necesarios para esbozar una reconstrucción paleoambiental del área que nos ocupa. Algunas de las hipótesis planteadas sobre cambios paleoclimáticos sólo pueden ser consideradas desde una perspectiva muy general, ya que desconocemos el impacto que las mismas pudieron producir en estos ambientes del NOA, debido a su complejidad geográfica y climática. Para el Formativo, a base de las fluctuaciones detectadas por Eddy, se plantea que entre el 300 a.C. y el 500 d.C. las sociedades altoandinas disfrutaron de una fase climática altamente bonacible (Cardich 1980). Por el contrario, para las tierras bajas, los estudios de Meggers y Dannon (citados en Brockington et al. 1995) indican la existencia de una gran sequía desde el 800 al 200 a.C. en el Amazonas y curso medio del Orinoco provocando una probable expansión temprana de las culturas amazónicas en los Andes orientales. Si a comienzos de la era la etapa bonacible en las tierras altas tuvo como correlato una etapa de aridez en el sector oriental podemos pensar que grupos de estas últimas zonas ocuparon y/o interactuaron más estrechamente con las poblaciones serranas. Con relación a los sitios tratados en este trabajo, solamente podemos decir que se emplazan en lugares hoy aptos para la instalación humana, razón por la cual consideramos que las observaciones del paisaje actual y de sus recursos económicos potenciales pueden ser válidas para elaborar inferencias sobre el pasado, si bien pudieron existir variaciones en el mosaico vegetacional.

5 En este trabajo se hace especial referencia a los contextos alfareros debido a que, por las características de preservación de estos sitios, no se han rescatado prácticamente otros materiales.

6 Nos referimos a los sitios de El Alfarcito, Estancia Grande, Antumpa, Til 22, Til 20, Pueblo Viejo de La Cueva y Sarahuaico, todos ellos están emplazados entre los 2.500 y los $3.500 \mathrm{msnm}$, en ambiente de prepuna y puna, en sectores ecotonales correspondientes a las cabeceras de quebradas subsidiarias al sistema principal de Humahuaca o sobre la misma quebrada de Humahuaca (TIL 20 y TIL 22). El tipo de asentamiento predominante es el de recintos dispersos en estructuras agrícolas, aunque en el caso de TIL 20 y TIL 22 no se puede determinar el tipo de asentamiento por las características de las excavaciones realizadas. Los recintos registrados son de forma redondeada y presentan bases de muros de piedra. Con relación a la tecnología cerámica predomina la cocción en atmósfera oxidante, aunque también se usó atmósfera reductora, el acabado es en general pulido. En cuanto a la decoración, prevalecen las cerámicas Alfarcito Gris Pulido, Marrón Castaño Pulida, Negro sobre Rojo (bandas gruesas quebradas) y Tricolor (quizá más tardías) y la técnica de pulido en líneas. La decoración incisa sólo aparece en Alfarcito, en tiestos con interior gris pulido. En las formas se destacan las grandes ollas tubulares (Estancia Grande y Antumpa) y los grandes cántaros subglobulares. Otros elementos artefactuales son: fragmentos de pipas de piedra, torteros, puntas de proyectil triangulares con pedúnculo, azadas y palas de piedra y madera e instrumentos de molienda. 